\title{
Financial Management Role for NGOs
}

\author{
Aleksandre Mikeladze
}

Associate Professor, PhD, Caucasus University

\section{Abstract}

The main purpose of NGOs is to carry out public activities and not financial management - this is an idea that one may have often heard. However, as long as the NGO's finances and funds are unorganized, NGOs will not be able to achieve their goals with maximum effectiveness. For NGOs, the key importance of financial planning and management is determined by the achievement of organizational goals. They work on communities, suffer from a lack of staff, and this role is assigned to an employee who does not have a financial education and puts the successful operation of the organization at high risk. With limited funding, rational and planned cash management is important for the organization. The financial condition of any type of organization determines its future and long-term stability. Accordingly, NGOs should opt for sustainable use of finance. This means that NGOs have to spend today considering future expenses. Therefore, it is important to develop financial plans and their further implementation in order to maintain sustainability. Most NGOs rely on external funding and therefore having a proper financial management system is quite important. The NGO is accountable to donors and those who support the organization. An NGO with a sound financial management system is able to track its own expenses, plan future expenses, and submit timely financial statements to the donor upon request, which will help strengthen the organization's trust and long-term support. All NGOs are guided by pre-defined policies and procedures that are based on the overall goals of the organization. Each decision made by the competent authority is aimed at the successful achievement of the goals and objectives. Without organizing finances, it will be difficult for both the individual employee and the organization as a whole to achieve the set goal. We cannot ignore the fact that some NGOs are characterized by illegal activities such as excessive use of resources, fraud, theft, etc. With full financial planning, coordination and control, the issues mentioned above can be easily addressed. Through sound financial management, NGOs can make effective decisions on resource allocation, fundraising and mobilization. Financial management is a set of skills and approaches that can be changed from time to time. With financial management, NGOs improve their profile, which enhances donor trust. With well-defined financial plan and policy frameworks, NGOs also gain a good reputation in the community. Most NGOs 
operate on their own funds, and well-organized financial management facilitates fundraising. Information on available finances, in turn, makes it possible to determine the exact amount of money that needs to be accumulated.

Keywords: financial management in NGOs, financial planning, control and reporting practices of NGOs, issues of accountability and transparency, financial sustainability of NGOs, benefits and risks of self-financing NGOs, the impact of income diversification on NGOs, good governance principles, impact of strategic planning of NGOs

\section{Introduction}

Many people have the impression that financial management only involves the production of accounting records. In fact, financial management facilitates the effective planning of current and future expenses, and it differs greatly from accounting.

The purpose of this study is to examine the role of financial management in the sustainability of NGOs. In many NGOs, financial management has a low priority, characterized by weak financial planning and monitoring systems. NGOs work in a fast-paced and competitive world. In order to establish themselves in this environment and achieve their goals, NGOs must be able to effectively analyze the financial information available to them.

Depending on the purpose of the research, the following tasks are set:

- Identify best management practices and NGO challenges based on reviews of existing literature and in-depth questionnaires

- Identify the areas where NGOs need to improve, including planning and budgeting, basic accounting systems, financial reporting, internal control, grant management, staffing, etc.

- Identify how well NGOs are in line with good financial practice

- Define the role of financial and fund management in NGOs

- Determine the impact of financial management on NGO activities

- Determine the effectiveness of NGOs through financial management

- Determine the methods of financial planning and control of NGOs

- Review NGO financial reporting practices

- Define NGO financial reporting and human capital development

- Determine the impact of accounting systems on financial reporting in NGOs 
- Identify accountability issues

- Analyze NGO accountability from a stakeholder theory perspective

- Review NGO governance: issues of accountability and transparency

- Identify the impact of internal controls on NGOs

- Determine the impact of internal controls on NGO financial reporting

- Identify the risk of financial mismanagement by NGOs

- Review the widespread problems of NGOs in developing countries

- Examine problems that threaten the survival of NGOs

- Identify determinants of NGO financial sustainability

- Identify the benefits and risks of self-financing NGOs

- Highlight the diversification of NGO income

- Examine the impact of income diversification on the commercialization of NGOs

- Identify the implementation of good governance principles

- Identify the impact of strategic planning on NGOs

Every organization is different, and financial management systems should reflect that. A "one size fits all" approach is ineffective. However, key aspects of good practice are the same for most organizations most of the time. The study focuses on these key aspects. They are the cornerstone of good practice.

\section{Financial Management in NGOs}

In present days, the role of NGOs has been increased significantly and with this increase, the role of financial management has become even more important to ensure the sustainability of NGOs and for achieving the set goals ${ }^{1}$.

NGOs face various problems, including the ineffective resource management. Funds management skills help build trust with partners as well as attract additional resources. With these resources, there comes a high need for management tools, e.g. budgeting and cash flow analysis that is an effective tool for planning and coordinating the ongoing or planned activities as well2. The financial performance of an NGO is important for sustainability, as well as for achieving the set goals ${ }^{3}$.

\footnotetext{
${ }^{1}$ Barry Strydom, Tim Stephen, Financial Management in Non-Profit Organizations: An Exploratory Study, 2014

2 Bharathi Karanth, Funds Management in Ngos-a Conceptual Framework, 2018

${ }^{3}$ Withz Aimable, the Effect of Financial Management on the Performance of Non-Profit Organizations,

An Emperial Study in Haiti, 2014
} 


\section{Performance Improvement of NGOs through Financial Management}

Strong financial management contributes to the efficient work of NGOs. If accounts are not managed properly, the organization will face some difficulties. Financial management is seen as defining, allocating and using financial resources to achieve the set goals and objectives. Measuring the effectiveness of NGOs is carried out by evaluating the achieved goals and results. Therefore, some studies show that there is a positive correlation between good governance and performance in achieving the set goals ${ }^{1}$.

\section{Financial Planning and Control Practices of NGOs}

Efficient financial management helps NGOs achieve their goals. Besides, without financial resources, NGOs will not operate effectively. Modern days, NGOs are getting used to modern financial practices, claiming to have reporting, budgeting and accounting in place ${ }^{2}$.

\section{Financial Reporting Practices of NGOs}

Financial reporting is one of the most important aspects of NGOs. Therefore, NGOs should define financial targets while considering annual planning and focus on the need for training staff in financial procedures. The agreement between the donor and organization is an important document that usually includes details related to budget, work plan, possible outcomes, etc. All actions should be carried out in accordance with the procedures that form the basis of the financial reporting considering the proper management of financial transactions, which will be followed by those responsible. Literature identifies the relationship between organization and the level of financial reporting. Organizations with bigger group of stakeholders are expected to disclose more financial information. ${ }^{3}$

Human capital development and financial reporting are assumed to be related. Human capital sets standards and provides a balance for financial reporting. Attributes to human capital include formal education, professional training, work experience. The quality of financial reporting is a matter of discussion and reflects financial accountability. Studies have identified the relationship between human capital and organizational productivity; increase in human capital have a positive

\footnotetext{
${ }^{1}$ Benedict Arthur, Performance Improvement of Non-Governmental Organizations Through Financial Management: Financial Management: a Case Study of Young Men's Christian Association of Ghana, 2020

2 Bharathi Karanth, Financial Planning and Control Practices of Selected Non-Governmental Organizations, An Empirical Appraisal, 2016

3 Yeaseen Chowdhury, Dr. Md. Mamun Habib, Financial Reporting Practices of Local Ngo's Operating in Bangladesh, 2019
} 
impact on organizational effectiveness. A skilled and educated, experienced employee with a good character positively influences relevance of financial reporting1.

\section{The Influence of Accounting Systems on Financial Accountability in NGOs}

Financial responsibility means no fraud and provides detailed explanations of financial activities, reporting to donors, ministries and other parties. Accountability aims to provide reports, justification of activities. Most donors require books of account and audited reports to increase transparency. Poor accountability can be a sign of a poor accounting system with weak control and monitoring measures. The accounting system consists of procedures and reports used by organizations to record transactions and provide feedback on results. The accounting system gives organizations a sense of direction and accountability. Financial responsibility deals with financial prospects and is designed for management and administration, where reporting practices increase NGO's accountability².

NGO accountability is a broad concept that is more complex than making it transparent. NGOs should set priorities for their stakeholders and commit to accountability. However, it is sometimes argued that if an NGO provides an evaluation of its performance, it may be unsatisfactory, raising concerns among future donors about providing funding. Even though, without accountability practices, NGOs risk its reputation that can cause funding loss. NGOs are already accountable to many parties, including members, donors, board members and others. NGOs depend heavily on reputation and trust for their existence, but providing inaccurate or misleading information puts the organization under the risk. Therefore, NGOs exercise their accountability in a variety of ways, including reporting, performance evaluation, public participation and self-regulation. NGOs can demonstrate that different types of accountability exist to ensure that they are responsible for actions that are well visible to society, with the increased public access to information through the Internet and the press, which means that being unaccountable is not an option, especially for smaller organizations ${ }^{3}$.

Weak accountability of NGOs can be judged by the financial reports that are presented to donors that lack information about community activities. According to the theory of agency relations, an agent hired by a principal is accountable to donors and the communities involved. Stakeholder theory is the relationship of stakeholders in the management decision-making process regarding resources and risks faced by an $\mathrm{NGO}$, while broader definition also includes the relationship between people and the environment. Stakeholder theory focuses on legitimacy associated with risks and moral claims. Stakeholder theory is a theory with a good basic concept that is used to provide information that users need based on their interests. Stakeholder theory

\footnotetext{
${ }^{1}$ Md Mostafijur Rahman, Ngo's Financial Reporting and Human Capital Development, 2016

2 Anas Rasheed Bajary, the Influence of Accounting Systems on Financial Accountability in Non-

Governmental Organizations, 2019

${ }^{3}$ Carol Ann Tilt, Ngos: Issues of Accountability, 2007
} 
explains different interests from an ethical or moral point of view and believes that individuals and groups are able to influence the goals of an organization by certain behaviors ${ }^{1}$. NGO accountability is transparency that allows stakeholders to use information and protect interests, and people have a right to know about NGOs' activities. Transparency is also important for beneficiaries, involved in program design and implementation. Stakeholder map analysis ensures that information is complete for the sake of accountability.

\section{Monitoring Power over NGO Performance}

Internal control systems are popular and important for financial reporting. However, the changing business environment is forcing executives to establish a reliable and effective control system. NGOs have relied on traditional and informal practices to support their operations. Internal control is intended to meet general objectives. It consists of procedures established by management to ensure that resources are used effectively and that actions are taken as effectively as possible.

Internal controls benefit organizations if they are functioning and can protect from fraud. To be effective, internal controls must be designed with organizational characteristics in mind and should respond to internal and external changes in the organization. It should be part of an organization's integrated enterprise risk management framework, where performance measurement serves as a planning tool for assessing impact. It also includes performance measurement, indicators to assess the NGO interventions along with the human resources, etc ${ }^{2}$.

\section{The Impact of Internal Control System on the Financial Accountability of NGOs}

Internal control can help an organization achieve its goals and its system includes policies and measures that provide management with assurance that the organization is achieving set goals and objectives. Among the objectives of internal control, there are other important ones, including security in action and maintaining operational effectiveness. Control is considered one of the most important aspects as it helps manage risks and ensure that certain actions are performed. Besides, risk assessment is taking place to assess factors that may affect the achievement of expected outcome. Accountability includes the obligation of people to provide clear information about their actions and can increase commitment and effectiveness. It increases the legitimacy of NGOs. Accountability will improve organizational performance. It is very important for NGOs to ensure that funding received from donors is used according to the goals and no amount is allocated to other goals. Internal controls are important to

\footnotetext{
${ }^{1}$ Ni Wayan Rustiarini, Accountability of Non-Government Organization from the Perspective of Stakeholder Theory, 2016

2 Moses Oppong, Alex Owiredu, Virgil Abedana, the Impact of Internal Control on the Performance of Faith-Based Ngos in Accra, 2016
} 
protect this aspect, improve data reliability, improve compliance with laws and increase the efficiency. ${ }^{1}$

\section{Risk of Financial Malpractice of NGOs}

Donor agencies have realized that corruption and other types of financial fraud can have a crucial impact on NGOs' activities. Several studies have looked at financial fraud in NGOs and assessed the risk of misuse of funds in NGOs and how can it be combatted. Based on the findings, the risk can be mitigated by stable collaboration and experience, shared between donors and implementing agencies. Studies also recommend that donors try to mitigate risks by adapting realistic financial control measures on the misuse of funds. Some studies have also tested a tool for assessing corruption risks from the perspective of the donors. The results identified important risk factors that donors and agencies need to take into account the NGO's capability and operational context ${ }^{2}$.

\section{The Widespread Challenges of NGOs in Developing Countries}

One of the most problematic aspects of NGOs is the decision-making process. Tensions have arisen between staff and the senior manager because of staff expectations, as they will be equal in the decision-making process. Another problem is related to staff career development. Common problems also include fundraising, limited experience in finances and management, ineffective self-sustainability. Other challenges also include accountability. To be successful, NGOs need to improve their performance and put more pressure on their management and leadership. New NGOs mostly suffer from limited resources, the trust of stakeholders and fundraising. The lack of developed goals and objectives, mission and values is another problem that NGOs face. For the most part, they are less effective and goals are unrealistic. It is very important to make the decision-making process effective for staff and management. Communication is also an important issue for NGOs, as well as trust and relationships with donors. Poor financial resources and institutional capacity, structural development and the desire to scale up activities are among the most discussed challenges ${ }^{3}$.

\section{Exploring the Challenges Threatening the Survival of NGOs}

Availability of funding is critical to the operations of NGOs, while inaccessibility of funds plays a weakening role for various institutions. Since most NGOs operate on a non-profit basis and depend on donations, survival becomes unpredictable.

\footnotetext{
${ }^{1}$ Abdulkadir Abdulrashid Rafindadi, Aliyu Zakariyah, the Impact of Internal Control System on the Financial Accountability of Non-Governmental Organizations in Nigeria: Evidence from the Structural Equation Modelling, 2019

2 Alhassan Musah, Financial Malpractice and Risk of Financial Malpractice of Ngos in Ghana:

Perspective of Donors, 2018

${ }^{3}$ Ali Akbar Bromideh, the Widespread Challenges of Ngos in Developing Countries, Case Studies from Iran, 2011
} 
Corruption, misuse of the organization's funds, paying ghost workers, and misuse of the organization's infrastructure, such as vehicles for personal use, damage the effectiveness of NGOs. It is possible that NGO directors may be connected to those in power and may not feel the law. The goal of NGOs may not be to solve social development problems, and they may not follow legal norms. Sometimes the lack of cooperation between an NGO and the government leads to inability to achieve goals and objectives ${ }^{1}$.

\section{Financial Sustainability of NGOs}

Social entrepreneurship in NGOs can be involved to achieve social goals. Entrepreneurs use their potential for social change. Although different ones limit the importance of social enterprise to a specific community task, this does not mean that organizations with existing products have to invent something new to have the features of a social enterprise. Products are mostly organic, e.g., local food, organic products, etc. Entrepreneurs get an economic advantage by expanding their ability to stay on their goals and at the same time, have a positive impact on society. NGOs can use their property to achieve their non-profit goals. Sustainability is measured by performance and effectiveness. Success is about integrating sustainability into organizational procedures, which is a key factor in their success. Sustainability has influenced the strategic orientation of NGOs. Financial sustainability is the ability of NGOs to diversify their funding base ${ }^{2}$.

The idea of sustainability among NGOs is not clearly stated. Sustainability is the ability of management to take care of the organization in the near future. An organization's financial sustainability is the ability to take advantage of opportunities and is usually combined with financial capacity. Financial sustainability is a key issue. Research from different developing countries has shown a number of things that determine the financial sustainability of NGOs. These factors include: diversification of financial benefits, sound financial management practices, generation of own income and good working relationship with donor partners. Financial sustainability is crucial to the survival of NGOs, and they are mostly struggling when they depend mainly on governmental funding. Therefore, NGOs should look for different ways to make their activities more sustainable. Financial sustainability is the ability of an NGO to raise funds or generate income in order to be able to perform necessary actions and can be measured by the difference between income and expenditure, as well as by the increase in income to emphasize the organization's liquidity and its ability to remain in working condition. In other literature, sustainability is viewed in terms of income diversification, goes beyond resource mobilization, sound financial management practices and is seen as the ability to adapt to changes in an ever-changing

\footnotetext{
${ }^{1}$ Simon Murote Kang'ethe, Tatenda Manomano, Exploring Challenges Threatening the Survival of Ngos in Selected African Countries, 2014

2 Hasan Metin, Bejtush Ademi, Financial Sustainability of Ngos: An Empirical Study of Kosovo Ngos, 2019
} 
environment. NGOs working on sustainability should be able to raise funds and hire staff to ensure support and cooperation with each other. Typically, the key to NGO financial sustainability is donor relationship management, revenue diversification, financial management techniques, etc. NGOs usually have high operating costs and rely mainly on public support for some of their projects. Some studies show that it is very important for NGOs to diversify their sources to ensure sustainability. In addition, these studies also showed that the lack of strategic financial planning is a problem for NGOs. The vast majority of NGOs have a strategic financial planning system to ensure that their goals are achieved. Reliable methods of financial management included the process of managing present and future financial resources and defining strategic planning for NGOs. Good financial management has a strong impact on sustainability because it helps to convince donors that NGOs have financial control that ensures that the funding received is used for the purposes or goals set. However, there is a great need for NGOs to be more accountable and transparent where financial management can play a role. The concept of measuring good financial management practice is to have financial plans linked to a strategic plan. Good financial management practice is when an NGO stores all information related to assets and liabilities and finds ways to reinvest to generate more income, and one of the best tools is to have a double entry system, all international financial reporting practices that help make the right decisions, which can also lead to diversifying income and increasing income from local or foreign sources. Diversifying income is when an organization is able to receive funding from a variety of sources, including state, international, private, etc. Revenue diversification is when more than half of the funding comes from five different sources. Some think that diversifying income means that half comes from international sources, other part from membership fees or community fundraising activities ${ }^{1}$.

Self-financing can be understood as a business to generate its own income and is the acquisition of internal sources bringing financial income and profit. It is strategically advantageous for an NGO to focus on self-supporting activities in line with its core mission. The risks of self-financing can be described in this concept as:

- Strong competition from the private sector

- The risk that the organization will forget its mission and become profitable is a priority ${ }^{2}$

The effective functioning of NGOs increasingly depends on financial sources that support their social goals. NGOs are not profit oriented, which is one of their main characteristics. The funds needed to implement a long-term idea aimed at supporting

\footnotetext{
${ }^{1}$ Alhassan Musah, Ahmed Ibrahim Anyass, Determinants of Financial Sustainability of NonGovernmental Organizations (Ngos) in Ghana, 2020

2 Gabriela Vaceková, Mária Svidroňová, Benefits and Risks of Self-Financing of Ngos - Empirical

Evidence from the Czech Republic, Slovakia and Austria, 2014
} 
society are mainly resources received from public and private donors. The implementation of a strategy based on income diversification is seen as a chance to increase income and strengthen stability of NGOs. Moreover, additional investment opportunities may lead to greater autonomy for organizations in their missionrelated work, which, at the same time, may lead to more effective monitoring of NGO functioning. Diversifying sources of income also helps limit the control of public and private donors, especially when any of them dominates the contribution of capital. Thus, it increases the independence of organizations in fulfilling their public mission and at the same time reduces the risk of pressure on NGO leaders to change or abandon the mission of the organization. NGOs are not profit oriented, which is one of their main characteristics. Missionary goals are mainly funded from several different sources. The strategy of diversifying income in NGOs is rejected for many reasons, which are mainly focused on widely perceived issues related to their independence and autonomy in fulfilling their social mission. Moreover, income diversification supports NGOs' financial security and improves their economic potential. Consequently, they must take a stronger market position and adapt to the conditions of stronger market participants. Access to many different sources of financial capital, on the one hand, limits the adaptation of non-profit organizations to areas of support imposed by government policies, and on the other hand, limits private donors. When any public or private support leads to capital investments, diversification of sources of income limits control by government agencies or individuals. Thus, it increases the independence of organizations in fulfilling their public mission, while reducing the risk of pressure on NGO leaders to change or abandon organization's priorities. Non-profit organizations with different income streams are less volatile and therefore less exposed to external factors such as recession. Diversifying income increases the likelihood that an organization will survive. At the same time, the authors argue that a higher level of income concentration increases the risk of bankruptcy of many organizations, especially during an economic downturn, when a decline in income from one source can be replaced by other financial sources. Non-profit organizations do not rely on one source of income, but their income is relatively concentrated. In another publication, the authors emphasize that this increases the autonomy of organizations in fulfilling their social mission and reduces pressure on managers of non-profit organizations to change or abandon their goals. Others explore the relationship between income diversification and the changing mission of the nonprofit organizations. They disprove previous studies, suggesting that access to many different sources of income reduces the variability of organizations. This effect depends on the structure of the portfolio. Based on the sources of funding rating, some note that national and foreign public funds are the most important for an organization given the scale of its social activity. NGOs that provide a wide range of services and products need different sources of funding. The way that nonprofit organizations use their chance to provide services is reflected in their social mission. NGOs try to obtain financial resources while at the same time fulfilling their goals that serve a particular social group. 
The way that nonprofit organizations use their chance to provide services is reflected in their social mission. Organizations try to obtain financial resources and at the same time to fulfill the adopted goals that serve a certain social group. However, the discussion about economizing the nonprofit sector is not without criticism of funding coming from commercial activities led by nonprofit organizations. This criticism mainly concerns the destruction of the social mission, which can often change or even abandon it. As many researchers note, from the financial point of view, it seems a justified choice to receive income from different sources. This provides an opportunity to increase their income and strengthen financial stability of NGO activities. Moreover, differentiation of investment opportunities may lead to greater autonomy of the organization. This facilitates more effective control over missionrelated activities. Income from commercial activities does not play an essential role in case of NGO mission change. Similarly, it is not public funding either at the national or local level, nor foreign foundations. When discussing the role of NGO financial sources in changing the mission, further research is needed. In addition, many factors affect the implementation of the social mission. Certain changes in the social mission implemented by NGOs are necessary and reflect changing social needs ${ }^{1}$.

\section{The Effect of Revenues Diversification on NGOs}

The problem of income diversification and its impact on stability has been observed. Commercialization of NGOs is a process in which NGOs perceived as nonprofit organizations involved in activities aimed at generating income from the sale of services and products. The goal of the commercialization process is to increase the economic stability of an organization through commercial sales of products and become independent from funding based on donations and/or charity, as well as from changes in the organization's leadership, with an emphasis on resourcefulness. Supporting the theory of dependence on source, researchers believe that non-profit organizations use commercial income. There are many reasons for the strategy of diversifying income sources in nonprofit organizations. It should be emphasized that both reasons for income diversification of the analyzed companies are closely interconnected and represent a desire to limit the risks associated with dependence on donors. Among the financial prerequisites, motive for diversifying the sources of income of NGOs is the fear of insolvency or decline in income. NGOs with diversified income are characterized by a stronger financial position than those that use only a few sources of income. Diversification of income increases the probability of survival of an organization. One condition of a stable NGO is access to different sources of funding. Financial stability is a key factor for NGOs because it not only supports planned activities, but also ensures that resources are available for hiring staff, purchasing equipment and maintaining jobs. Stability of funding ensures not only continuity of NGO activities, but also predictability and manageability. Regular access

${ }^{1}$ Paweł Mikołajczak, Diversification of Ngos' Revenues: Implications for the Mission Changeability, 2019 
to the organization's finances creates opportunities for its continuous work. Concentration of financing on several stable sources contributes to the growth of organizations, ensuring greater financial stability. One way to diversify the income of a non-profit organization is to receive it from the commercial sale of goods and/or services in exchange for payment. The essence of the process of commercialization is to create economic stability for the nonprofit organization by ensuring its independence from donations or philanthropic funding and changes in its management, with an emphasis on entrepreneurship and the self-sustainability of the organization ${ }^{1}$.

\section{NGOs and the Implementation of Good Governance Principles}

Good governance is a popular word, which has attracted public attention in the last decade. This concept is rapidly becoming an important in considering the ability of a state to meet generally accepted democratic standards. It seems that many countries around the world are seeking to use available resources to ensure the development of their society, which is a positive step towards good governance. The introduction of good governance principles into NGOs is being actively discussed in an international forum and in developer circles. There was no universal definition or single author that would actually explain satisfactorily what good governance means in NGOs or how they should apply it to help vulnerable communities. In most scenarios, good governance was closely linked to community affairs and how to properly manage enterprises or community resources. Most NGOs see themselves as catalysts for change and participants affected by external changes, such as capacity development, in the context of development discussions. NGOs can reorient and expand their activities by applying their skills and knowledge in a variety of areas, from training, information sharing, counseling and advisory services, as a way to facilitate change in other institutions whose responsibilities include providing support services to the government. NGOs see capacity building as a process through which a society, or changes its rules, institutions and standards of conduct, increases its social capital, which increases its ability to respond, adapt and discipline itself. The authors reflect on the idea that, as part of improving good governance, NGOs and donor agencies share costs of capacity building, reflecting the growing awareness that contributes to the allocation of resources and contributions that help improve an organization's performance. Implementing human resources policies and working procedures is critical for NGOs in good governance practices. In any organization, the effective implementation of quality control largely depends on the quality of the personnel working. NGOs in developing countries have an obligation to implement effective human resource initiatives through the adoption of various human resource policies, ranging from recruitment, training and promotion, monitoring and evaluation, compensation and other measures. For example, in hiring the workforce,

\footnotetext{
1 Paweł Mikołajczak, the Impact of the Diversification of Revenues on Ngos' Commercialization: Evidence from Poland, 2018
} 
NGOs should look for standards to ensure that they recruit qualified staff with extensive experience and knowledge and demonstrate ethical standards for the job. The authorities should ensure that transactions are approved by responsible officials to avoid unnecessary costs to the organization. NGO managers should play an oversight role by hiring managers who play a fundamental role in implementing effective control systems for effective management. This requires regular compliance checks in accordance with relevant operating procedures. These procedures entail what, how, why, where and when actions will be taken. Control and monitoring procedures were also important elements in ensuring good governance in NGOs. As the NGO sector expands in terms of funding and functions, concerns about professionalism and accountability are growing. Good governance includes many characteristics such as participation, rule of law, transparency, responsiveness, consensus orientation, fairness and inclusiveness, efficiency and effectiveness, and accountability. Transparency and openness, in turn, imply that decisions are made and implemented in accordance with rules and regulations ${ }^{1}$.

\section{The Impact of Strategic Planning for NGOs}

Strategic planning is crucial to the strategic management process. Strategic planning is an integral part of the organization and is deeply rooted in providing clarity of purpose, followed by developing mechanisms that create value for NGOs. Strategic planning includes internal and external analysis, i.e. PEST or SWOT analysis. Some link the mission and strategy to the performance of the organization. Others think that maintaining proper alignment between mission and goals helps the implementation process. Financial accounting helps NGOs keep track of how well they utilize scarce resources and funds. The information obtained contributes to the NGO's accountability and additional fundraising. Internal processes are more cost related, and revision of internal processes depends on performance indicators. The success of an NGO depends on skills and competence. Therefore, an NGO needs to periodically improve the skills of its employees, manage information exchange, which will lead to an overall increase in productivity. In addition, training and volunteer development methods should also increase productivity. All of this is very important for strategic planning that improves the performance of $\mathrm{NGOs}^{2}$.

\section{Research Methodology}

The research combines theoretical, quantitative and qualitative methods. Relevant Georgian and foreign language literature and data are obtained at the initial stage of

\footnotetext{
${ }^{1}$ Elvin Shava, Non-Governmental Organizations and the Implementation of Good Governance Principles, 2016

2 Rohana Bandara Weerasooriya, a. Chamaru De Alwis, Ali Khatibi, the Impact of Strategic Planning for Non-Government Organizations in Sri Lanka: An Evaluation Using the Balanced Scorecard Development of a Conceptual Framework, 2014
} 
the research through in-depth interviews with NGOs based on pre-designed questionnaires.

Interviews are an excellent method for our research as they provide in-depth information about managers' opinions, experiences and challenges within the research. Interviews are effective because the topic to be addressed covers issues that require a complex approach. Face-to-face interviews provide maximum extraction of information.

Different types have been considered during the interview, including:

- Structured Interviews: The interviewer ask standard, pre-defined questions in a specific sequence. The respondent chooses his / her answer from the possible answers.

- Unstructured Interviews: In a non-structured interview, the interviewer had no specific guidelines, restrictions, pre-defined questions. The interviewer asked some general questions to participate in an open, informal, and spontaneous discussion.

In addition, within the framework of the research, researches of international organizations have been found on the Internet, on the basis of which literature, documents and secondary information have been analyzed, scientific papers, various reports have been collected. The document analysis method was used as an independent method to obtain important information on the research topic. Internet was used to collect documents. The search was carried out mainly on the basis of electronic scientific databases. In some cases, popular search engines, including www.google.com has been used. To collect data, different keyword combinations and free access documents have been used posted on scientific online platforms. It is important that no research in this area has been conducted in Georgia yet and this research is the first precedent in Georgia.

The research paper identifies the health of NGOs' financial management and assesses tool so that NGOs can identify the areas where they need to improve. Besides, all key areas of NGOs financial management are covered to consider how well organizations are in line with good practice.

\section{Discussion}

Based on the study, we can conclude that in NGOs:

- Managers are more likely to take an active interest in financial management issues

- Senior management leads by example and adheres to financial policies and procedures

- Program personnel typically adhere to accounting procedures and requirements 
- Nonfinancial staff are consulted on the practicality and "usability" of financial documents (e.g., vehicle logs, payment forms, and expense claims)

- Financial personnel are known to be available and willing to discuss issues with program staff

- The finance department is "evaluated" by the organization - e.g., it is adequately resourced; it is represented on the management team

- Finance personnel are engaged in the strategic planning process

- Budgets are delegated, managed, and implemented at the project level

- Financial personnel are involved in the annual budgeting process

Research has shown that the following is not always true:

- Program staff job descriptions establish specific financial management roles and responsibilities

- Program staff receive financial management training, either through formal courses

- Program staff never complains that financial policies and procedures are too bureaucratic or not practical

- If any employee fails to follow policies and procedures, it results in some kind of sanction or warning (as opposed to people getting away with it)

- Financial policies and procedures are written down (e.g., in the Financial Manual) and distributed to all staff

- Finance and program staff meet regularly to discuss program plans and progress toward goals

- Program staff receive regular budget monitoring reports and use them to manage their programs

- Chart of accounts (list of account codes/categories) is available to program staff

- Program staff participate in the annual budgeting process

Mostly NGOs have a reasonable level of integration of financial management. But NGOs could easily improve matters with some careful planning. Other enhancements can be very helpful in avoiding misunderstandings and conflicts; making procedures more efficient; helping staff do their jobs better and more efficiently; and making more effective use of resources. For instance, a good first step might be to review the findings of the self-assessment with some of NGOs managers and discuss what NGOs can do better. 
In most situations, NGOs have a fair degree of integration in financial management. However, NGOs can improve quickly with proper preparation. Further changes can help avoid misunderstandings and conflicts; make processes more effective; help workers to do their job faster and more effectively; and make more productive use of resources. For example, a successful first step might be to study the outcomes of selfassessment with some NGO leaders and explore which NGOs should do better.

\section{Planning and budgeting}

Research shows that these is the most common finding:

- Budgets are developed in a timely manner for all organizational operating costs

- Project budgets are based on planned operating costs

- A distinct budget is established for overhead

- Organizational budgets are endorsed by the Board

- Most anticipated operational costs are appropriately funded

- Most of the time, a cash flow forecast is prepared on a monthly basis

However, the following occurrences rarely took place:

- Financial and program staff assist with budgeting

- Budget sheets include explanatory notes and clear computations

- A designated person (budget holder) is responsible for implementing and administering each budget

- Budget codes align with accounting codes

\section{Basic accounting system}

Based on the research, it was identified that mostly:

- A supporting document is attached to each payment made

- All incoming cash or cheques are recorded on pre-numbered receipts in PDF format

- All payments and receipts are accounted for in cash books (date, description, amount)

- A separate cashbook exists for each bank and cashier account

- Each entry in the cash registers is referred to a supporting document

- All cash books are carefully produced in permanent ink or by computer 
- A standard chart of accounts is used to code (or classify) each operation into cash records

- A bank reconciliation is conducted monthly for each bank account

- Cash counts are reconciled and recorded on a monthly basis

- The organization tracks amounts owed to others (e.g., vendors) and owed by others (e.g., staff)

However, the following has taken place rarely:

- All cash books are updated a minimum of once a month

- Transactions are also categorized by project or donor through a standard list of "cost centers"

\section{Financial Reporting}

Based on the research, it was identified that mostly:

- Financial reports are discussed by senior management at least once every three months

- Reports include details of cash and bank balances, amounts owing and owned

- Financial reporting serves for decision making

- However, the following has taken place rarely:

- The Board examines the financial reports on a quarterly basis

- Budget managers receive budget tracking reports each month

- Budget tracking reports include explanations and comments on differences

- Financial information is provided to beneficiaries at least annually in an accessible manner

- Annual audits are up to date (signed in the 6 months following the end of the financial year)

\section{Internal controls}

Based on the research, it was identified that mostly:

- All cash received is banked intact, i.e. without any being spent

- There is a detailed written policy that may allow expenditures of different types or values.

- All transactions are duly authorized

- Different stages of the procurement process (e.g., ordering, receiving and paying) are shared between different people 
- Personnel salaries are audited monthly by an executive

- Mandatory deductions (e.g. payroll taxes) are done right and paid on time

- An approved policy and procedure manual is available which is relevant to the organization and known to employees

However, the following has taking place rarely:

- Money is kept securely in a safe or under lock and key is in the care of a single person

- All cheques are signed by two or more signing officers

- Cheques are not signed until all details have been correctly completed (i.e. no signatory has ever signed a blank cheque)

- Bank reconciliations are verified by a person that did not prepare them

- Cash payments are authorized by a person who is not the cashier

- Claims for personnel advances are verified by the same person who authorized the advance

- All capital assets (e.g. vehicles, computers, equipment) owned by the NGO are insured and monitored through a capital register

- The trustees shall select a duly registered verification firm

\section{Grant management}

Based on the research, it was identified that mostly

- A signed grant agreement is available for each grant

- Senior management checks that grant terms are reasonable before signing agreements

- Financial staff, budget officers and procurement officers know the terms and conditions of the procurement within grants

- Grant agreement terms and conditions are well respected

- Funders receive financial reports in the correct format and in a timely manner

- Financial and narrative reports from funders are coherent and clearly linked

- Funder funds are maintained for the activities for which they are intended and are never "borrowed" for other activities

\section{Staffing}

Based on the research, it was identified that mostly 
- The board includes an individual who is qualified to oversee all financial activities

- Finance personnel have the necessary competencies (and qualifications) to perform all financial activities

- Program managers and personnel are financially competent to manage budgets and implement controls

- Finance staff and budget officers work well together on payment processing and budget tracking

- The various roles within the finance function are clearly defined, recognized and respected

- Senior managers set an example by using control procedures

- All personnel are provided with the training and support they require to fulfill their financial management responsibilities

However, the following has taking place rarely:

- Finance staff are hired freely and fairly on a merit basis only

Generally, there is clearly some good financial practice in place, but still plenty of room for improvement. There is a risk that financial problems will prevent NGOs from doing work. Sometimes, there is a high need that require attention from managers.

\section{Findings, Conclusion and Recommendations}

Budgeting means estimating the future costs of planned activities. Consequently, financial planning should include not only financial staff, but also project staff, which will also provide a good basis for cooperation. In addition, it is also important that board members are aware of budgets and approve them in advance to ensure that the strategic direction of the organization is not changed. Budgets are important to ensure effective financial management. The appointee must keep track of the ongoing costs associated with the programs and ensure that the appropriate codes are used for budget items that are also linked to the accounting codes. Tracking actual costs versus planned costs will also allow the manager to make appropriate changes. In addition, it is important to conduct a cash flow analysis, which is just as important as budgeting. A forecast should be made for at least 3 months, based on available cash flow. The analysis will help managers prioritize the timing and duration of planned activities and identify cash flow problems in time.

Each financial transaction must be accompanied by appropriate documentation, including invoices, receipts, etc., which serve as evidence of the specific transaction in question. Each transaction must be recorded accordingly. In this case, an Excel 
spreadsheet, accounting software or paper can be used. It is very important to check that the balance sheet is correct each month.

It is important for board members to have financial statements in order to know the financial position of the organization. Managers need to have up-to-date information to monitor the project and take appropriate action. Donors need reports to support the use of funds, which, in many cases, influence decisions about further funding. In addition, organizations share information with beneficiaries to build trust and accountability. In addition, external audits verify the accuracy of financial reporting.

It is important that monthly financial reports include income and expenditure information. In addition, project managers should ignore financial reports to make appropriate decisions to make sure that money is used correctly and is producing the desired results. Reports should be prepared at the end of each month in an appropriate format.

NGOs should have a system of internal controls to ensure the accuracy of accounting records, protect assets, and prevent fraud.

Many NGOs receive a portion of their funding from donors with a specific grant agreement. Donor-funded projects have specific requirements that are also part of the agreement and may include a number of grant conditions. Finance staff must work with project staff to ensure that the financial report and narrative are consistent. Sometimes NGOs work with different donors. It is important to keep track of where donor funds are distributed and how they are used. Using funds from another project for an NGO is not good practice.

Staff must have the right skills for effective financial management. The accounting department includes executive management, managers, etc. who incorporate effective financial management into programs, ensuring that the financial staff works with the budget assigned staff at all stages.

\section{Results}

At present, Georgian scholars have developed no literature or research related to the role of financial management in non-governmental organizations at a time when there is a high interest in this issue in the international scientific community. Financial management issues are quite relevant for NGOs as any NGO strives to achieve financial sustainability. For this, it is necessary to analyze finances for future planning. The results of the study are important to individuals involved in the management of the NGO or to other stakeholders. The research process revealed a combination of general and specific factors of financial management that affect the success of an NGO. In addition, interesting theoretical considerations related to the issue and NGO's sustainability factors have been identified. The results obtained adequately and purposefully addresses the sustainability of the NGO and plays an important role for those interested in the issue. Also, local best practices, internal standards of the 
organization was analyzed and a number of recommendations have been developed to promote the sustainability and growth of the NGO. This research will help NGOs to better plan their activities. In addition, it will help the NGO decision maker to plan well for future activities without compromising financial stability.

\section{Acknowledgments}

I would like to thank the Caucasus University, which made it possible to prepare this study as part of its grant competition.

In addition, I would like to express appreciation to all the interviewees for their continued support and encouragement for participating in the interviews and nongovernmental bodies for providing all the needed data and/or information for conducting this research.

\section{Bibliography}

[1] Abdulkadir Abdulrashid Rafindadi, Aliyu Zakariyah, The Impact Of Internal Control System On The Financial Accountability Of Non-Governmental Organizations In Nigeria: Evidence From The Structural Equation Modelling, 2019

[2] Alhassan Musah, Ahmed Ibrahim Anyass, Determinants Of Financial Sustainability Of Non-Governmental Organizations (Ngos) In Ghana, 2020

[3] Alhassan Musah, Financial Malpractice And Risk Of Financial Malpractice Of Ngos In Ghana: Perspective Of Donors, 2018

[4] Ali Akbar Bromideh, The Widespread Challenges Of Ngos In Developing Countries, Case Studies From Iran, 2011

[5] Anas Rasheed Bajary, The Influence Of Accounting Systems On Financial Accountability In Non-Governmental Organizations, 2019

[6] Barry Strydom, Tim Stephen, Financial Management In Non-Profit Organizations: An Exploratory Study, 2014

[7] Benedict Arthur, Performance Improvement Of Non-Governmental Organizations Through Financial Management: Financial Management: A Case Study Of Young Men's Christian Association Of Ghana, 2020

[8] Bharathi Karanth, Financial Planning And Control Practices Of Selected Non-Governmental Organizations, An Empirical Appraisal, 2016

[9] Bharathi Karanth, Funds Management In Ngos-A Conceptual Framework, 2018

[10] Carol Ann Tilt, Ngos: Issues Of Accountability, 2007

[11] Elvin Shava, Non-Governmental Organizations And The Implementation Of Good Governance Principles, 2016 
[12] Gabriela Vaceková, Mária Svidroňová, Benefits And Risks Of Self-Financing Of Ngos - Empirical Evidence From The Czech Republic, Slovakia And Austria, 2014

[13] Hasan Metin, Bejtush Ademi, Financial Sustainability Of Ngos: An Empirical Study Of Kosovo Ngos, 2019

[14] Md Mostafijur Rahman, NGO's Financial Reporting And Human Capital Development, 2016

[15] Moses Oppong, Alex Owiredu, Virgil Abedana, The Impact Of Internal Control On The Performance Of Faith-Based Ngos In Accra, 2016

[16] Ni Wayan Rustiarini, Accountability Of Non-Government Organization From The Perspective Of Stakeholder Theory, 2016

[17] Paweł Mikołajczak, Diversification Of Ngos' Revenues: Implications For The Mission Changeability, 2019

[18] Paweł Mikołajczak, The Impact Of The Diversification Of Revenues On Ngos' Commercialization: Evidence From Poland, 2018

[19] Rohana Bandara Weerasooriya, A. Chamaru De Alwis, Ali Khatibi, The Impact Of Strategic Planning For Non-Government Organizations In Sri Lanka: An Evaluation Using The Balanced Scorecard - Development Of A Conceptual Framework, 2014

[20] Simon Murote Kang'ethe, Tatenda Manomano, Exploring Challenges Threatening The Survival of Ngos In Selected African Countries, 2014

[21] Withz Aimable, The Effect Of Financial Management On The Performance Of Non-Profit Organizations, An Emperial Study In Haiti, 2014

[22] Yeaseen Chowdhury, Dr. Md. Mamun Habib, Financial Reporting Practices Of Local NGO's Operating In Bangladesh, 2019 